\title{
Applicability of the Rey Auditory-Verbal Learning Test to an adult sample in Brazil
}

\section{O Teste de Aprendizagem Auditivo-Verbal de Rey: aplicabilidade para uma amostra de adultos brasileiros}

\author{
João Vinícius Salgado, ${ }^{1,2,4}$ Leandro Fernandes Malloy-Diniz, ${ }^{3,4,5,6}$ Suzana Silva Costa Abrantes, ${ }^{6}$ Lafaiete \\ Moreira, ${ }^{5,6}$ Carlos Guilherme Schlottfeldt, ${ }^{4,6}$ Wanderlane Guimarães, $^{7}$ Djeane Marcely Ugoline Freitas, ${ }^{7}$ \\ Juliana Oliveira, ${ }^{7}$ Daniel Fuentes ${ }^{6,8}$

\footnotetext{
${ }^{1}$ Department of Morphology, Instituto de Ciências Biológicas (ICB), Universidade Federal de Minas Gerais (UFMG), Belo Horizonte, MG, Brazil ${ }^{2}$ Hospital de Ensino Instituto Raul Soares, Belo Horizonte, MG, Brazil

${ }^{3}$ INCT de Medicina Molecular, School of Medicine, Universidade Federal de Minas Gerais (UFMG), Belo Horizonte, MG, Brazil

${ }^{4}$ Post-Graduation Program in Neurosciences, Universidade Federal de Minas Gerais (UFMG), Belo Horizonte, MG, Brazil

${ }^{6}$ Laboratórios Integrados de Neuropsicologia (LINEU), Universidade Federal de Minas Gerais (UFMG), Belo Horizonte, MG, Brazil

7 Occupational therapist

${ }^{8}$ Psychology and Neuropsychology Service, Instituto de Psiquiatria, Hospital das Clínicas, Faculdade de Medicina, Universidade de São Paulo
} \\ ${ }^{5}$ Post-Graduation Program in Molecular Medicine, Universidade Federal de Minas Gerais (UFMG), Belo Horizonte, MG, Brazil \\ (USP), São Paulo, SP, Brazil
}

\begin{abstract}
Objective: The Rey Auditory-Verbal Learning Test, which is used to evaluate learning and memory, is a widely recognized tool in the general literature on neuropsychology. This paper aims at presenting the performance of Brazilian adult subjects on the Rey Auditory-Verbal Learning Test, and was written after we published a previous study on the performance of Brazilian elderly subjects on this same test. Method: A version of the test, featuring a list of high-frequency one-syllable and two-syllable concrete Portuguese substantives, was developed. Two hundred and forty-three (243) subjects from both genders were allocated to 6 different age groups $(20-24 ; 25-29 ; 30-34 ; 35-44 ; 45-54$ and 55-60 years old). They were then tested using the Rey Auditory-Verbal Learning Test. Results: Performance on the Rey Auditory-Verbal Learning Test showed a positive correlation with educational level and a negative correlation with age. Women performed significantly better than men. When applied across similar age ranges, our results were similar to those recorded for the English version of the Rey Auditory-Verbal Learning Test. Conclusion: Our results suggest that the adaptation of the Rey Auditory-Verbal Learning Test to Brazilian Portuguese is appropriate and that it is applicable to Brazilian subjects for memory capacity evaluation purposes and across similar age groups and educational levels.
\end{abstract}

Descriptors: Memory; Auditory perception; Learning; Neuropsychological tests; Adult

\section{Resumo}

Objetivo: $O$ Rey Auditory-Verbal Learning Test é um teste mundialmente reconhecido na literatura neuropsicológica que avalia o aprendizado e a memória. Na sequência de um estudo anterior, que apresentou o desempenho dos idosos brasileiros no Rey Auditory-Verbal Learning Test, este trabalho apresenta o desempenho dos adultos brasileiros no Rey Auditory-Verbal Learning Test. Método: Uma versão do teste foi desenvolvida com uma lista de alta frequência, com uma ou duas sílabas de substantivos concretos do português do Brasil. Duzentos e quarenta e três (243) individuos de ambos os sexos foram alocados para seis faixas etárias (20-24, 25-29, 30-34, 3544, 45-54 e 55-60 anos) e avaliados com o Rey Auditory-Verbal Learning Test. Resultados: O grau de escolaridade e idade mostrou correlação positiva e negativa, respectivamente, com o desempenho no Rey Auditory-Verbal Learning Test. As mulheres tiveram um desempenho significativamente melhor que os homens. Os resultados foram semelhantes aos encontrados para a versão em inglês do Rey Auditory-Verbal Learning Test por meio de faixas etárias semelhantes. Conclusão: Nossos resultados sugerem que a adaptação do Rey Auditory-Verbal Learning Test para o português brasileiro é adequada e aplicável para avaliação da capacidade de memória de individuos brasileiros, com idade e nivel educacional similar.

Descritores: Memória; Percepção auditiva; Aprendizagem; Testes neuropsicológicos; Adulto
Submitted: April 1, 2010

Accepted: August 25, 2010
Correspondence

Leandro Fernandes Malloy-Diniz

Faculdade de Filosofia e Ciências Humanas, Departamento de Psico-

logia, Universidade Federal de Minas Gerais

Av. Antônio Carlos, 6627

31270-901 Belo Horizonte, MG, Brasil

E-mail: malloy.diniz@gmail.com 


\section{Introduction}

The Rey Auditory-Verbal Learning Test (RAVLT) is a useful and easy to perform neuropsychological task based on a wordlist-based learning paradigm. The test measures several components of verbal memory such as immediate recall, verbal learning, susceptibility to both proactive and retroactive interference, retention of information after a certain period of time during which other activities are performed, and recognition memory.

RAVLT was originally developed by Rey ${ }^{1}$ and later modified by authors from several countries, where the test has been recognized as a useful tool for diagnosing memory disturbances. ${ }^{2,3}$

In countries where English is the main spoken language, there are several studies providing parameters for result interpretation ${ }^{4-7}$ when the test is applied to different age groups. In Brazil, normative standards have been developed for the 16 to 89 yearold age bracket. ${ }^{8}$ Nonetheless, the cited study adopted a translated version of the wordlist originally used in English speaking countries, without considering both the frequency at which these translated words are used in Brazilian Portuguese and the number of syllables of each word from the lists. Another version used a list of high-frequency, one or two-syllable Portuguese substantives ${ }^{9}$ as stimuli to assess the performance of Brazilian senior citizens aged 60 to 89 years. ${ }^{10}$ The rationale behind the inclusion of words that frequently appear in Portuguese was that the test would be used to evaluate individuals from all social groups and educational levels. This study aims at assessing how well adults aged 20 to 59 years can perform on this new version of the RAVLT.

\section{Method}

\section{Participants and procedure}

Two hundred and forty-three individuals from both genders whose ages varied between 20 and 59 years-old were evaluated. Enrollment in the study was made possible through local advertisements placed at two university campuses and one social club. Subjects were distributed into seven age-based groups: 20-24; 25-29; 30-34; 35-44; $45-54$ and 55-59 years old.

Participants did not refer any cognitive impairment, psychiatric or neurological disturbances, and had not been on any psychotropic medication for at least three weeks. This information was obtained using a semi-structured interview, which was carried out before the memory assessment. All subjects had received at least eight years of formal education.

The RAVLT was applied and corrected according to the same process previously described in Malloy-Diniz et al. ${ }^{10}$

\section{Approval by the Ethics Committee}

This study was approved by the Research Ethics Committee of Hospital Felício Rocho, state of Minas Gerais, Brazil (CEP/FR 129/05). All participants signed a consent form declaring that they had been properly informed of the purposes of the study.

\section{Statistical analysis of the results}

After calculating the respective mean and standard deviations, a descriptive statistical analysis was carried out for each measure. A
General Linear Model (UNIANOVA) was developed using gender, age group and educational level i.e., elementary school, secondary school (incomplete), secondary school (complete), undergraduate or graduate studies (incomplete) and undergraduate or graduate studies (complete) as factors, and each RALVT measure as the dependent variable. The performance of each age group was compared to that of another group to look for differences found for each RAVLT cognitive variable. A value of $\mathrm{p}<0.05$ was considered statistically significant for all tests.

\section{Results}

The parametric distribution nature was confirmed based on the interpretation of the Skewness and Kurtosis indices for the data's descriptive analysis. The analysis of the age-group factor showed significant differences in the following RAVLT measures: A1 $[\mathrm{F}=3,022(\mathrm{p}=0.007)] ; \mathrm{A} 3[\mathrm{~F}=2.310(\mathrm{p}=0.034)]$; A6 $[\mathrm{F}=2.317(\mathrm{p}=0.034)] ; \mathrm{B} 1[\mathrm{~F}=5.943(\mathrm{p}<0.001)] ; \mathrm{A} 7[\mathrm{~F}=$ $2.539(\mathrm{p}=0.021)]$; recognition $[\mathrm{F}=2.571(\mathrm{p}=0.019)]$ and learning during the attempts $[\mathrm{F}=2.197(\mathrm{p}=0.044)]$. The other measures didn't show significant differences, as follow: A2 [F = $1.919(\mathrm{p}=0.078)] ;$ A4 $[\mathrm{F}=1.157(\mathrm{p}=0.330)] ;$ A5 $[\mathrm{F}=0.938$ $(\mathrm{p}=0.468)]$; proactive interference $[\mathrm{F}=0.750(\mathrm{p}=0.610)]$; retroactive interference $[F=1.682(\mathrm{p}<0.126)]$ and forgetting speed $[\mathrm{F}=0.904(\mathrm{p}=0.492)]$.

Fisher LSD post-hoc analysis revealed that, for the A1 variable, the 20-24 and the 25-29 age groups outperformed the 35-44, 45-54 and 55-59 age groups. The same occurred for B1, but the 30-34 age group performed significantly worse than the younger groups in this variable. For variables A3, A6 and recognition, only the group aged 55-59 presented different results compared to that of other groups. For A7, with the exception of the 45-54 age group, all groups presented different results compared to the 55-59 and 35-44 age group was also different from the 45-54 group. As far as the earning during the attempts measure, the 35-44 group outperformed the 25-29 and 55-59 age groups, and the 45-54 group outperformed the 25-29 group.

In all age groups, men performed significantly worse in A6 [F = $6.451(p=0.012)]$, retroactive interference $[F=5.176(p=0.024)]$ and learning during the attempts $[\mathrm{F}=3.930(\mathrm{p}=0.048)]$. With respect to the other measures, no difference was seen between men and women.

We found only an interaction between age group and gender in forgetting speed $[\mathrm{F}=2,292(\mathrm{p}=0.036)]$.

The analysis of the educational-level factor showed significant differences in $\mathrm{A} 1[\mathrm{~F}=2.581(\mathrm{p}<0.038)]$ and $\mathrm{B} 1[\mathrm{~F}=4.281(\mathrm{p}=$ 0.002)]. Considering the A1 trial, Fisher LSD post-hoc analysis revealed that subjects with incomplete undergraduate or graduate studies performed better than subjects from both the complete and incomplete elementary and secondary school groups. Considering the B1 trial, subjects who had completed their undergraduate studies performed better than those who had either fully or partially attended only elementary and secondary schools. We found interaction between age group and educational level in the B1 trial $[\mathrm{F}=1,540(\mathrm{p}=0.038)]$. 


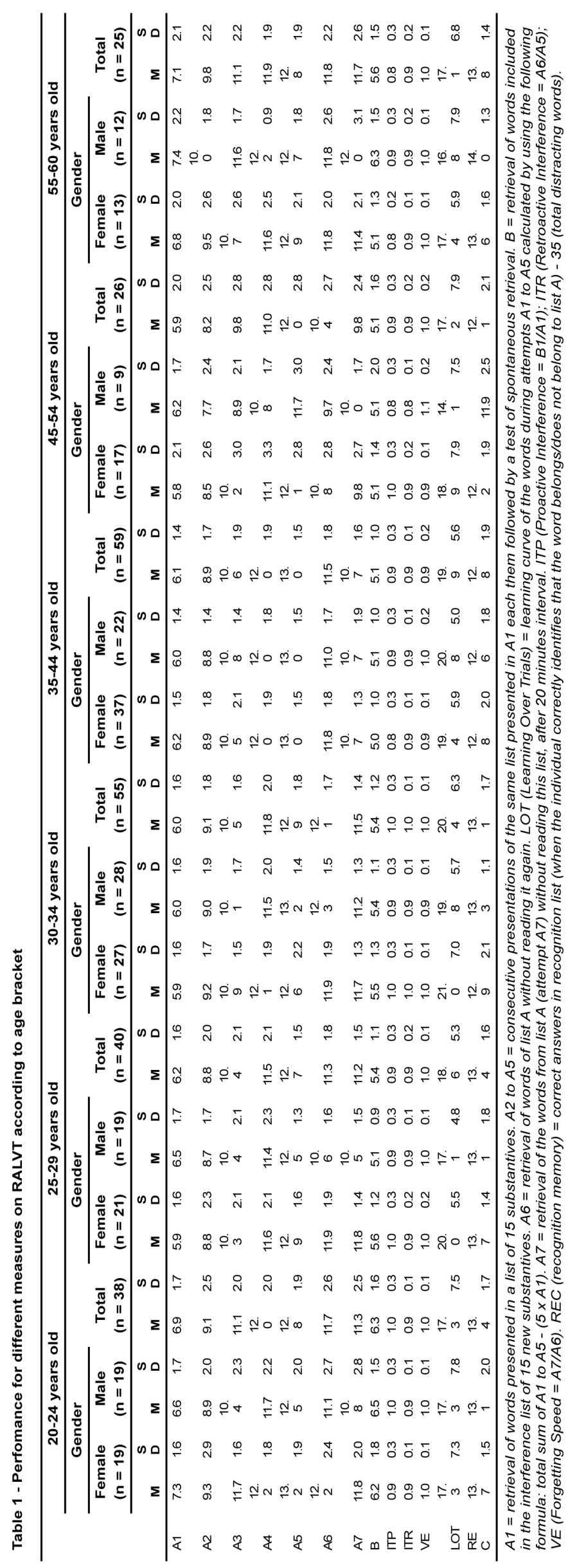

The results for the different age groups, according to gender and age, are described in Table 1.

\section{Discussion}

In general, our results are consistent with reports that age is the most influential demographic feature in RAVLT performance. However, this influence is weaker in the groups aged 20-39 and stronger in the groups aged 40-59., ${ }^{2,11}$ In our study, most measures (A3, A6, A7, recognition) showed differences only between the oldest group (55-59) and the other groups, except in the case of A7, where the performance of the 50-55 group was different from that of the 35-54 group. In A1 and B1, however, the two youngest groups outperformed the groups above 35 years of age, and in B1, the group aged 25-29 also outperformed the 30-34 age group. Our results, therefore, suggest that age has a different impact on memory variables depending on one's stage in life. The variable learning during the attempts showed interesting results since the best performance was seen in the groups aged 35-44 and 45-54. These findings suggest that these groups performed worse than the younger groups in A1, however, it seems that their performance in trials does compensate this handicap.

As recommended by Geffen et al., 5 proactive and retroactive interference, as well as forgetting speed, were calculated using quotients rather than differences. No differences in results were seen among age groups regarding these quotients, which is consistent with the results reported by other authors, ${ }^{5,12}$ thus indicating that age has little influence on these abilities.

The influence of the educational level was limited to A1 and B1 trials. A recent study conducted with a Brazilian adult sample suggesting that the articulatory loop of the working memory could be particularly affected by educational level found similar results for A1. ${ }^{13}$ This study also found a relationship between educational level and performance in A1, but not in B1. These discrepancies could be justified by the use of different age groups, as well as different ranges of educational level in relation to our sample. Another study identified a certain connection between educational level and performance in all RAVLT' measures analyzed, except learning. ${ }^{14}$ Nonetheless, in a recent meta-analysis carried out by Mitrushina et al., educational level didn't substantially contribute to test performance. ${ }^{15}$ The relationship between educational level and other variables, such as age and intelligence, should be contemplated by future studies on RAVLT performance.

According to our results, gender also influenced performance in the RAVLT. Women outperformed men in A6, retroactive interference and learning during the attempts. In the literature, there are reports that woman either outperformed men in recall trials but not in the recognition trial, ${ }^{2,5,12,16}$ or that woman outperformed men in recall and recognition. ${ }^{13}$ There is also a study that fails to show female superiority. ${ }^{3}$ Our results are consistent with the notion that, in general, women perform better in recall trials, but not in the recognition trial. Nevertheless, it appears that, in the RAVLT, influence of gender is weaker compared to that of age. 
Our findings point out to the existence of certain discrepancies between our study and that of Malloy-Diniz et al. ${ }^{8}$ Since we divided our subjects aged between 18 and 59 into seven different age groups, this study's sample was better characterized compared to the previotus study. Furthermore, differently from the previous study, women performed better in this study than men in certain test sets (A6, retroactive interference and learning during the attempts). Considering that Malloy-Diniz et al. used a smaller sample, this difference could be explained on the basis of this study's sample size.
A limitation of this study is that our subjects have a high level of formal education, and that subjects with psychiatric and neurological symptoms were excluded. As a result, we could expect our sample to have a better cognitive performance compared to that of the overall population.

Studies using subjects from different socio-economic backgrounds, as well as other clinical populations are being performed to contribute with more information about this test's validity.

Disclosures

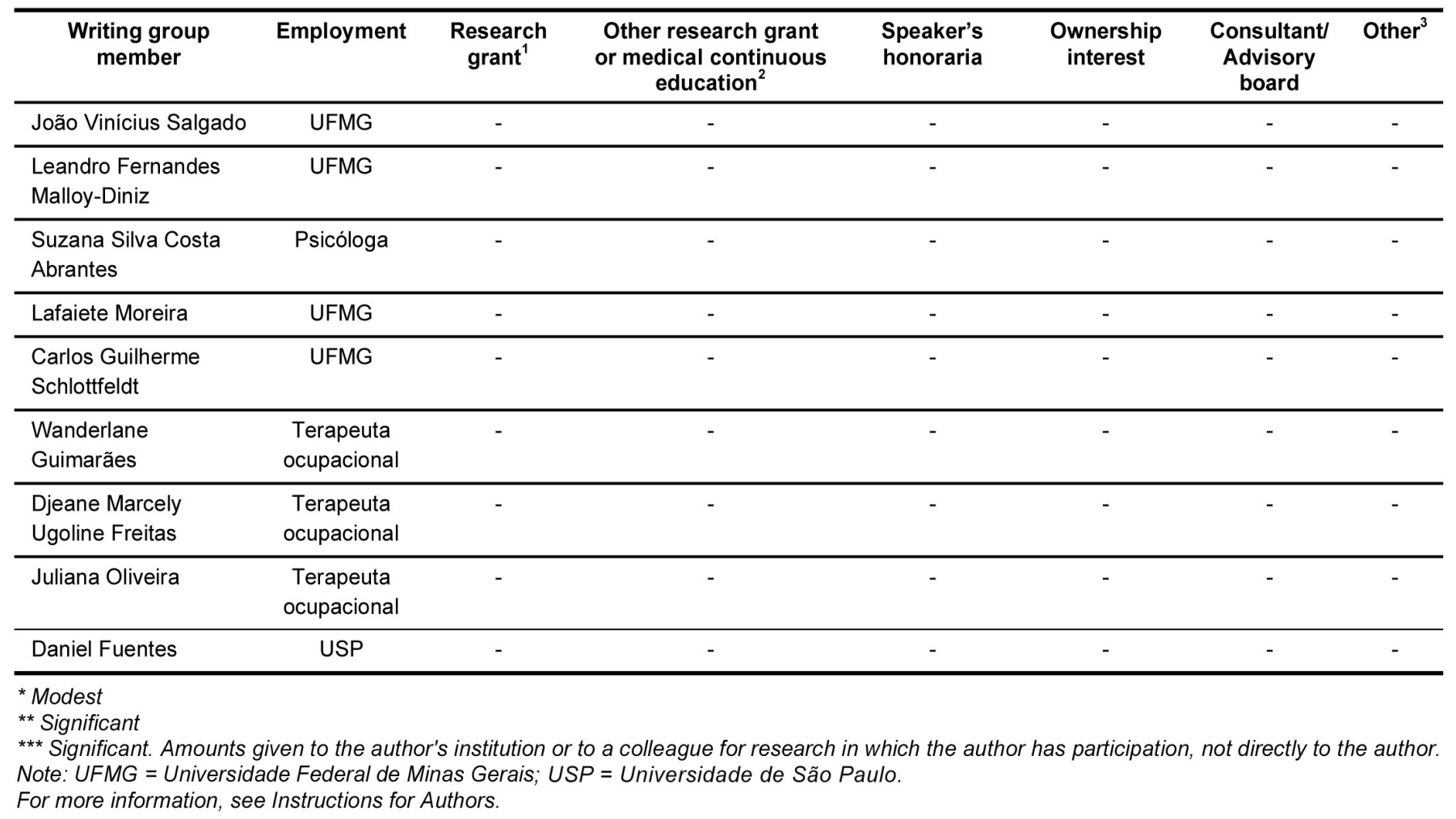

References

1. Rey A. L'Examen clinique en psychologie. Paris: Press Universitaire de France; 1958. 2._Messinis L, Tsakona I, Malefaki S, Papathanasopoulos P. Normative data and discriminant validity of Rey's Verbal Learning Test for the Greek adult population. Arch Clin Neuropsychol. 2007; 22(6):739-52.

3. Schoenberg MR, Dawson KA, Duff K, Patton D, Scott JG, Adams RL.Test performance and classification statistics for the Rey Auditory Verbal Learning Test in selected clinical samples. Arch Clin Neuropsychol. 2006;21(7):693-703.

4. Wiens NA, McMinn MR, Crossen JR. Rey auditory-verbal learning test: development of norms for healthy young adults. Clin Neuropsychol. 1988;2:67-87. 5. Geffen G, Moar KJ, O’Hanlon AP, Clark CR, Geffen LB. Performance measures of 16 to 86 -year-old males and females on the auditory verbal learning test. Clin Neuropsychol. 1990;4:45-63.

6. Mitrushina M, Satz P, Chervinsky A, D'Elia L. Performance of four age groups of normal elderly on the Rey auditory-verbal learning test. J Clin Psychol. 1991;47(3):351-7.

7. Gale SD, Baxter L, Connor DJ, Herring A, Comer J. Sex differences on the Rey Auditory Verbal Learning Test and the Brief Visuospatial Memory Test-Revised in the elderly: normative data in 172 participants. J Clin Exp Neuropsychol. 2007;29(5):561-7.

8. Malloy-Diniz LF, da Cruz MF, Torres V, Cosenza R. O teste de aprendizagem auditivo-verbal de Rey: normas para uma população brasileira. Rev Bras Neurol. 2000;36(3):79-83.
9. Malloy-Diniz LF, Fuentes D, Abrantes S, Lasmar V, Salgado JV. O teste de aprendizagem auditivo verbal de Rey. In: Malloy-Diniz LF, Fuentes D, Mattos P, Abreu N. Aval Neuropsicológica. Porto Alegre: ARTMED; 2010. p.337-43.

10. Malloy-Diniz LF, Lasmar VA, Gazinelli Lde S, Fuentes D, Salgado JV. The Rey auditory-verbal learning test: applicability for the Brazilian elderly population. Rev Bras Psiquiatr. 2007;29(4):324-9.

11. Vakil E, Blachstien H. Rey auditory verbal learning test: developmental norms for adults, and sensitivity of different memory measures to age. Clin Neuropsychol. 1997;11:356-69.

12. Bolla-Wilson $\mathrm{K}$, Blecker ML. Influence of verbal intelligence, sex, age, and education on the Rey Auditory Verbal Learning Test. Dev Neuropsychol. 1986;2(3):203-11.

13. van der Elst W, van Boxtel MPJ, van Breukelen GJP, Jolles J. Rey's verbal learning test: Normative data for 1855 healthy participants aged 24-81 years and the influence of age, sex, education, and mode of presentation. J Int Neuropsychol Society. 2005;11(3):290-302.

14. Teruya LC, Ortiz KZ, Minett TSC. Performance of normal adults on Rey auditory learning test: a pilot study. Arq NeuroPsiquiatr. 2009;67(2A):224-8.

15. Mitrushina M, Bone K, D'Elia L. Handbook of normative data for neuropsychological assessment. New York: Oxford University Press; 2005.

16. Lannoo E, Vingerhoets G. Flemish nomative data on common neuropsychological tests: Influence of age, education, and gender. Psychol Belgica. 1997;37(3):141-56. 